\title{
Usage of diuretics among diabetic-hypertensive patients
}

\author{
Rajeshwari Shastry1, M.R. Prabha Adhikari², Sheetal D. Ullal ${ }^{3}$, Shashidhar Kotian ${ }^{4}$ \\ ${ }^{1}$ Assistant Professor, Department of Pharmacology, Kasturba Medical College Mangalore, Manipal University, Manipal, Karnataka, India, \\ ${ }^{2}$ Professor, Department of Medicine, Kasturba Medical College Mangalore, Manipal University, Manipal, Karnataka, India, ${ }^{3}$ Associate Professor, \\ Department of Pharmacology, Kasturba Medical College Mangalore, Manipal University, Manipal, Karnataka, India, ${ }^{4}$ Selection Grade Lecturer, \\ Department of Community Medicine, Kasturba Medical College Mangalore, Manipal University, Manipal, Karnataka, India
}

Background: Hypertension is more common in diabetics than in non-diabetic patients. An aggressive approach to the diagnosis and treatment of hypertension in patients with diabetes is required in order to substantially reduce the incidence of both macro-vascular and microvascular complications. The role of diuretics in the treatment of hypertension as first line or second line drugs is a provoking debate, hence we studied the usage of diuretics and their effects on BP and glycemic control among diabetic-hypertensive patients. Methods: This cross sectional study was carried out for a period of six months in a tertiary care teaching hospital. Patients' details such as age, gender, height, weight, comorbid diseases, blood pressure, eGFR along with duration of diabetes and hypertension and drugs prescribed for hypertension were noted. Data were analyzed using descriptive statistics. Results: A total of 336 diabetic-hypertensives with a mean age of $64.55 \pm 9.51$ years were included. Fortyfive patients were on diuretics, two (4.4\%) of whom were on diuretic monotherapy, 16 (35.6\%) on two drug combinations (Diuretic + ACEI or ARB), 21 (46.7\%) on three drug combinations (diuretics + ARB \& BBs or diuretic + ACEI \& BB or diuretic + ARB \&CCB) and six (13.3\%) were on four drug combinations (diuretics + ARB, CCB \& BB). Among the patients on diuretic combination therapy BP was well controlled in $23(51 \%)$ patients and the glycemic control was comparable to those not on diuretics. Conclusion: In the present study the usage of diuretics was consistent with the guidelines. About $13 \%$ of diabetic-hypertensive patients were on diuretic treatment. The control of BP in patients on diuretics was not satisfactory, but there was no worsening of glycemic control compared to other antihypertensive therapy. This shows that low dose thiazides in combination with other antihypertensives can be safe in diabetic-hypertensive patients however their efficacy needs further scrutiny.

Keywords: Diabetes mellitus, Diuretics, Hypertension, Thiazides
Access this article online Website:

http://nepjol.info/index.php/AJMS DOI: 10.3126/ajms.v6i2.10582

\section{INTRODUCTION}

Hypertension is a common comorbid condition in diabetes; it is 1.5 to three times more common in patients with diabetes than in those without diabetes. ${ }^{1}$ The world diabetes capital, India, in the next thirty years may also be the world hypertension capital. ${ }^{2}$ Hypertension and diabetes mellitus (DM) are both important contributory factors for the growing burden of cardiovascular and chronic kidney disease. ${ }^{3}$ Achieving the recommended goal of blood pressure $(<130 / 80 \mathrm{~mm} \mathrm{Hg})$ in hypertensives with DM is difficult in a majority of patients. ${ }^{4,5}$ An aggressive approach to the diagnosis and treatment of hypertension in patients with diabetes is required in order to substantially reduce the incidence of both macro-vascular and micro-vascular complications. The anti-hypertensive agents used in diabetic patients should not only aim at controlling hypertension but also at preventing/delaying the development of complications. ${ }^{6}$ Several factors are important in selecting anti-hypertensive agents for diabetic-hypertensive patients.

Guidelines for the treatment of hypertension recommend that thiazide diuretics should be the preferred drugs in most hypertensive patients, including in diabetics, either alone or combined with drugs from other classes. ${ }^{7}$ Diuretics have been used effectively to treat hypertensive patients 
in the past four decades. Although thiazide and thiazidelike diuretics are indispensable drugs in the treatment of hypertension, their role as first-line or even second-line drugs among diabetics is a provoking debate. ${ }^{8}$ Recently diuretics received less enthusiasm compared with newer agents, and their role in the treatment of diabetic patients has been scrutinized due to the potential for adverse effects on glucose and lipid levels and the physiologic response to hypoglycemia. ${ }^{9}$ Hence this study was undertaken to analyse the usageof diuretics and their effects on BP and glycemic control among diabetic-hypertensive patients.

\section{MATERIALS AND METHODS}

This cross sectional study was carried out for a period of six months in a tertiary care teaching hospital. Patients with both diabetes and hypertension were included in the study after getting approval from the institutional ethics committee and obtaining a written informed consent from the patients. Patients' details such as age, gender, height, weight, comorbid diseases, blood pressure [Systolic blood pressure (SBP), Diastolic blood pressure(DBP)], eGFR along with duration of diabetes and hypertension and drugs prescribed for hypertension were noted on a proforma. Data were analyzed using descriptive statistics.

\section{RESULTS}

A total of 336 diabetic patients with hypertension were included in the study, $163(48.5 \%)$ were males \& $173(51.5 \%)$ were females. The mean age of the study population was $64.55 \pm 9.51$ years. Table 1 shows the demographic and clinical data of the study population.

Among the 336 diabetic-hypertensive patients, 45(13.4\%) were on diuretics. The diuretics used by them were hydrochlorothiazide (45 patients), furosemide (28 patients) and spironolactone (23 patients). Diuretics were used in combination with other antihypertensive groups like ARBs, ACEIs, BB and CCB. Out of the 45 patients on diuretics two patients (4.4\%) were on diuretic monotherapy, 16 patients $(35.6 \%)$ were on two drug combinations, 21 patients $(46.7 \%)$ were on three drug combinations and

\begin{tabular}{lc}
\hline \multicolumn{2}{l}{ Table 1: Demographic and clinical data of } \\
diabetic-hypertensive patients \\
\hline Characteristics & $\begin{array}{c}\text { Mean } \pm \text { SD } \\
\text { (N=336) }\end{array}$ \\
\hline Age (years) & $64.55 \pm 9.51$ \\
Duration of DM (years) & $10.83 \pm 8.74$ \\
Duration of HTN (years) & $7.39 \pm 6.91$ \\
SBP (mmHg) & $138.17 \pm 13.11$ \\
DBP (mmHg) & $82.05 \pm 6.17$ \\
\hline
\end{tabular}

six patients $(13.3 \%)$ were on four drug combinations. In two drug combinations along with diuretics ACEIs were prescribed the most, followed by ARBs. In three drug combinations along with diuretics $\mathrm{ARBs}$ plus $\mathrm{BBs}$ were highest followed by ACEIs plus BBs and ARBs plus CCBs. In four drug combination diuretics with $\mathrm{ARB}, \mathrm{CCB} \& \mathrm{BBs}$ were commonly prescribed (Table 2).

Among the ARBs losartan and telmisartan; among the ACEIs enalapril and ramipril; among the beta blockers atenolol and metoprolol and among the CCBs amlodipine were the agents used. Commonly used antihypertensive agents along with diuretics were losartan (17 patients), amlodipine (16 patients) and enalapril (13 patients).

The comorbidities that were present in the 45 patients on diuretics were dyslipidemia (14 patients), ischemic heart disease (12 patients), peripheral neuropathy (13 patients), nephropathy (4 patients), cerebrovascular accident and retinopathy (3 patients).

Table 3 shows the effects of diuretic combination therapy and other antihypertensive therapy on blood pressure and glycemic control. Among the 45 patients who were on diuretics, the blood pressure was well controlled

\begin{tabular}{lc} 
Table 2: Prescribing pattern of diuretics with \\
other antihypertensive drug groups \\
\hline Drug combination & N=45 (\%) \\
\hline Diuretics alone & $2(4.44)$ \\
2 drug combinations & $1(2.22)$ \\
Diuretic+BBs & $1(2.22)$ \\
Diuretic+CCBs & $6(13.33)$ \\
Diuretic+ARBs & $8(17.77)$ \\
Diuretic+ACEls & \\
3 drug Combinations & $5(11.11)$ \\
Diuretic+ACEls+BBs & $4(8.88)$ \\
Diuretic+ACEls+CCBs & $1(2.22)$ \\
Diuretic+ACEls+ARBs & $6(13.33)$ \\
Diuretic+ARBs+BBs & $5(11.11)$ \\
Diuretic+ARBs+CCBs & \\
4 drug Combinations & $4(8.88)$ \\
Diuretic+ARBS+CCBs+BBs & $1(2.22)$ \\
Diuretic+ACEls+ARBs+CCB & $1(2.22)$ \\
Diuretic+ACEls+CCBs+BBs &
\end{tabular}

Table 3: Effects of antihypertensive combination therapy on blood pressure and glycemic control

\begin{tabular}{lcc}
\hline Drug therapy & $\begin{array}{c}\text { Controlled } \\
\text { (N) (\%) }\end{array}$ & $\begin{array}{c}\text { Not } \\
\text { controlled } \\
(\mathbf{N})(\%)\end{array}$ \\
\hline Blood pressure & & \\
$\quad$ Diuretic combination therapy $(\mathrm{N}=45)$ & $23(51)$ & $22(49)$ \\
$\quad \begin{array}{l}\text { Other antihypertensive therapy }(\mathrm{N}=291) \\
\text { Glycemic Control }\end{array}$ & $217(75)$ & $74(25)$ \\
$\quad$ Diuretic combination therapy $(\mathrm{N}=45)$ & $18(40)$ & $27(60)$ \\
$\quad$ Other antihypertensive therapy $(\mathrm{N}=291)$ & $117(40)$ & $174(60)$ \\
\hline
\end{tabular}


$(\leq 140 / 90 \mathrm{~mm}$ of $\mathrm{Hg})$ in $23(51 \%)$ patients and there was a good glycemic control $\left(\mathrm{HbA}_{1 \mathrm{C}}<7\right)$ in $18(40 \%)$ patients.

\section{DISCUSSION}

Diuretics are used in hypertension because of their efficacy, low cost, synergistic effect when used in combination with other antihypertensive agents and the fact that they counteract salt and fluid retention caused by other antihypertensive agents; and, also their beneficial effects in patients with heart failure. Thiazide diuretics are the first choice of agents in non-diabetic patients, but there has been a tendency to avoid their use in patients with diabetes due to concerns over adverse metabolic effects, despite evidence that these are minimal when lower doses are used. ${ }^{10} \mathrm{High}-$ dose diuretics have detrimental effects on glycemic control as well as on triglyceride and cholesterol. ${ }^{11}$ Hence low-dose diuretics are now more commonly prescribed. Low-dose diuretics are noted to augment the anti-hypertensive effects of other major groups of antihypertensive agents and therefore work well in combinations. ${ }^{12}$ In a previous study diuretics were prescribed in $28 \%$ of diabetic hypertensive patients. ${ }^{13}$ In our study only $13.4 \%$ (45 patients) of the diabetic-hypertensive patients were on thiazides which were prescribed in low dose (hydrochlorothiazide 6.25 to $25 \mathrm{mg} /$ day), probably because of the concern of adverse effect on glycemic control and hyponatremia in the elderly. Among those 45 patients, only two patients were on monotherapy whereas all others were on low dose of diuretics in combination with other antihypertensive agents. The $\mathrm{HbA} 1_{\mathrm{C}}$ of the two patients on diuretic monotherapy was $7 \& 7.7 \%$ and the mean $\mathrm{HbA} 1_{\mathrm{C}}$ of all the patients on diuretics was $7.7 \pm 1.41 \%$, which was satisfactory. ${ }^{14}$ The glycemic control was similar in both the study groups (i.e. patients on diuretic combination therapy and patients not on diuretics). Among the 45 patients on diuretics, $18(40 \%)$ had $\mathrm{HbA} 1_{\mathrm{C}}<7$, while $117(40 \%)$ patients not on diuretics had $\mathrm{HbA} 1_{C}<7$, which is considered as wellcontrolled. ${ }^{14}$ Hence thiazides in low doses can be safely used in diabetic hypertensive without much change in the glycemic control.

Current antihypertensive guidelines recommend BP goal for diabetic patients as $<140 / 90 \mathrm{mmHg}^{7}$ In the present study in $22(49 \%)$ patients receiving diuretic combination therapy and in $74(25 \%)$ patients who were not on diuretics, this recommended goal of BP was not met. This shows that use of low dose diuretics may not be very efficacious in controlling hypertension, though there was no deleterious effect on the glycemic control compared to other antihypertensive agents. However, one of the limitations of this inference is that there may be other confounding factors apart from the use of diuretics which may have affected the control of BP; but analysis of these factors was beyond the scope of our study.

There were 28 patients on furosemide. Furosemide is indicated in patients with impaired renal function. The mean eGFR of the patients on furosemide was $50.9 \pm 22.12 \mathrm{ml} / \mathrm{min}$ hence furosemide may have been prescribed in these patients.

Most diabetic-hypertensive patients require more than one agent to attain adequate blood pressure control. Renin Angiotensin Aldosterone System (RAAS) inhibitor and a diuretic combination will offset the diuretic-induced increase in plasma renin activity. The salt loss will add to the antihypertensive effect of RAAS blocker. ARB will also attenuate the metabolic adverse effects (like hypokalemia and hyperglycemia) of thiazide diuretics. ${ }^{15} \mathrm{In}$ the present study along with diuretics ARBs and ACEIs were the commonly prescribed antihypertensive groups followed by BBs and CCBs, which is in accordance with the recommended guidelines. ${ }^{4,16}$ The maximal use of thiazide diuretics with RAAS inhibitors is comparable to the earlier report by Ethiraj Dhanaraj et al. ${ }^{17}$ Angiotensinconverting enzyme (ACE) inhibitors prevent or delay microvascular and macrovascular complications of diabetes, delay progression of diabetic kidney disease and are recommended as first-line antihypertensive agents in patients with diabetes. ARBs may be used in patients who cannot tolerate ACE inhibitors. If adequate titration of the ACE inhibitor or ARB does not provide satisfactory blood pressure reduction, addition of a thiazide diuretic is the next step. If blood pressure is not controlled with the addition of a beta blocker, a CCB should be added.,18,19 In our study the same pattern of antihypertensive use was noted which is consistent with the guidelines.

Fourteen patients $(31.11 \%)$ who were on diuretic therapy had dyslipidemia. Hypertension and dyslipidemia can coexist frequently. Among the antihypertensive agents ARBs have shown to improve insulin sensitivity and reduce triglyceride levels ${ }^{20,21}$ and this could be one of the reasons for the higher usage of $\mathrm{ARB}$ in combination with diuretics in our study.

In our study along with diuretic, next to losartan, amlodipine was used the most. Controversy exists regarding the use of CCBs, particularly the dihydropyridines in treating diabetic-hypertensives. Some studies showed higher incidence of cardiac events in diabetic patients treated with dihydropyridine $\mathrm{CCBs}$, as compared with ACE inhibitors. ${ }^{22,23}$ In other studies, ${ }^{24-26}$ the use of dihydropyridine CCBs, as monotherapy or in combination with another antihypertensive agent, was associated with a reduction in cardiovascular risk. 


\section{CONCLUSION}

In the present study the usage of diuretics was consistent with the guidelines. About $13 \%$ of diabetic-hypertensive patients were on diuretic treatment. The control of BP in patients on diuretics was not satisfactory, but there was no worsening of glycemic control compared to other antihypertensive therapy. This shows that low dose thiazides in combination with other anti hypertensives can be safe in diabetic-hypertensive patients however their efficacy needs further scrutiny.

\section{REFERENCES}

1. Arauz-Pacheco $C$, Parrott $M A$ and Raskin $P$ for the American Diabetes Association. Hypertension management in adults with diabetes. Diabetes Care 2004; 27(S1):S65-S67.

2. Joshi SR and Parikh RM. India - Diabetes capital of the world: Now heading towards hypertension. J Assoc Physicians India 2007; 55:323-324.

3. Dash SC and Agarwal SK. Incidence of chronic kidney disease in India. Nephrol Dial Transplant 2006; 21:232-233.

4. American Diabetes Association: Standards of medical care in diabetes. Diabetes Care 2010; 33:11-61.

5. Ong KL, Cheung BM, Man YB, Lau CP and Lam KS: Prevalence, awareness, treatment, and control of hypertension among United States adults 1999-2004. Hypertension 2007; 49:69-75.

6. Patel BM and Mehta AA. Choice of antihypertensive agents in diabetic subjects. DiabVasc Dis Res 2013; 10(5):385-396.

7. James PA, Oparil S, Carter BL, Cushman WC, DennisonHimmelfarb C, Handler J, et al. Evidence-Based Guideline for the Management of High Blood Pressure in Adults: Report From the Panel Members Appointed to the Eighth Joint National Committee (JNC 8). JAMA 2014; 311(5):507-520.

8. Grossman E, Verdecchia P, Shamiss A, Angeli F and Reboldi G. Diuretic treatment of hypertension. Diabetes Care 2011; 34:S313-S319.

9. Sander GE and Giles TD. Thiazide Diuretics and b-Blockers in the Treatment of Hypertension in Diabetes Mellitus. J Clin Hypertens 2011; 13(4):296-300.

10. Harper R, Ennis CN, Heaney AP, Sheridan B, Gormley M, Atkinson $A B$, et al. A comparison of the effects of low- and conventional-dose thiazide diuretic on insulin action in hypertensive patients with NIDDM. Diabetologia 1995; 38: 853-859.

11. MacLeod MJ and McLay J. Drug treatment of hypertension complicating diabetes mellitus. Drugs 1998; 56: 189-202.

12. Brown MJ, Cruickshank JK, Dominiczak AF, MacGregor GA, Poulter NR, Russell GI, et al. Better blood pressure control: How to combine drugs. J Hum Hypertens 2003; 17: 81-86.
13. Datta $S$ and Udupa AL. Antihypertensive drug use in patients having comorbid diabetes: cross sectional prescription pattern study in a tertiary care hospital. Asian Journal of Pharmaceutical and Clinical Research 2010;3(4):43-45.

14. ICMR guidelines for management of type 2 diabetes-2005. Available at http://icmr.nic.in/guidelines_diabetes/section4.pdf

15. Kalra S, Kalra B and Agrawal N. Combination therapy in hypertension: An update. Diabetol Metab Syndr 2010; 2 (1):44.

16. Mancia G, Laurent S, Agabiti-Rosei E, Ambrosioni E, Burnier M, Caulfield MJ, et al. Reappraisal of European guidelines on hypertension management: A European Society of Hypertension Task Force document. J Hypertens 2009; 27(11): 2121-2158.

17. Dhanaraj E, Raval A, Yadav R, Bhansali $A$ and Tiwari $P$. Prescription Pattern of Antihypertensive Agents in T2DM Patients Visiting Tertiary Care Centre in North India. Int J Hypertens 2012;2012:520915

18. American Diabetes Association. Standards of medical care in diabetes - 2008. Diabetes Care 2008; 31(suppl 1):S12-S54.

19. KDOQI. KDOQI clinical practice guidelines and clinical practice recommendations for diabetes and chronic kidney disease. Am J Kidney Dis.2007; 49(2 Sup 2):S12-S154.

20. Inoue T, Morooka T, Moroe K, Ikeda $\mathrm{H}$ and Node K. Effect of Telmisartan on Cholesterol Levels in Patients with Hypertension - Saga Telmisartan Aggressive Research (STAR). Horm Metab Res 2007; 39:372-376.

21. Schupp $M$, Clemenz $M$, Gineste $R$, Witt $H$, Janke J, Helleboid S, et al. Molecular characterization of new selective peroxisome proliferators-activated receptor $\mathrm{Y}$ modulators with angiotensine receptor blocking activity. Diabetes 2005; 54(12):3442-3452.

22. Estacio RO, Jeffers BW, Hiatt WR, Biggerstaff SL, Gifford N and Schrier RW. The effect of nisoldipine as compared with enalapril on cardiovascular outcomes in patients with non-insulindependent diabetes and hypertension. N Engl J Med 1998; 338(10): 645-652.

23. Konzem SL, Devore VS and Bauer DW. Controlling Hypertension in Patients with Diabetes. Am Fam Physician 2002; 66(7):1209-1214.

24. Hansson L, Zanchetti A, Carruthers SG, Dahlof B, Elmfeldt D, Julius $S$, et al. Effects of intensive blood-pressure lowering and low-dose aspirin in patients with hypertension: Principal results of the Hypertension Optimal Treatment (HOT) randomised trial. Lancet 1998; 351(9118):1755-1762.

25. Tuomilehto J, Rastenyte D, Birkenhager WH, Thijs L, Antikainen R, Bulpitt CJ, et al. Effects of calcium-channel blockade in older patients with diabetes and systolic hypertension. Systolic Hypertension in Europe Trial Investigators. N Engl J Med 1999; 340(9):677-684.

26. Wang JG, Staessen JA, Gong L and Liu L. Chinese trial on isolated systolic hypertension in the elderly. Systolic Hypertension in China (Syst-China) Collaborative Group. Arch Intern Med 2000;160(2):211-220.

\section{Authors Contribution:}

RS - Designed the study, analysed the data, drafted the manuscript, \& reviewed the manuscript; PAMR - Designed the study \& reviewed the manuscript; SDU - Analysed the data \& drafted the manuscript; SK - Analysed the data.

Source of Support: Nil, Conflict of Interest: None declared. 